thương đốt sống vùng lưng và thắt lưng. 2006.

7. Stoffel, M., et al., Treatment of painful osteoporotic compression and burst fractures using kyphoplasty: a prospective observational design. Journal of Neurosurgery: Spine, 2007. 6(4): p. 313-319.

\title{
HIỆU QUẢ CẢI THIỄN SỐ LƯợNG TIỂU CẦU CỦA THUỐC KHÁNG VIRUS TRỰC TIẾP Ở BỆNH NHÂN VIÊM GAN VIRUS C MẠN TÍNH
}

\section{TÓM TẮT}

Mục tiêu: Khảo sát hiệu quả cải thiện số lượng tiểu cẩu của thuốc kháng virus trực tiếp ở bệnh nhân viêm gan virus $C$ man tính. Đối tương và phương pháp: Mô tả cắt ngang hồi cứu trên 109 hồ sơ bệnh án của bênh nhân viêm gan virus $C$ man đến khám và điều trị ngoại trú tại Phòng khám viềm gan - Bệnh viên Đại hoc Y Dược TP. Hồ Chí Minh, thời gian từ tháng 01/2016 đến 6/2020. Bệnh nhân được chỉ định điều trị bằng các phác đồ thuốc kháng virus trực tiếp (DAA) (không có IFN và ribavirin) và có xét nghiệm số lượng tiểu câuu trước, trong và sau khi kết thúc điều tri 12 tuần. Kết quả: Tuổi trung bình trong nghiên cứu là $58,3 \pm 12,6$, với tỷ lê nữ nhiêu hơn nam và bênh nhân không xớ gan chiếm tỷ lệ cao. Số lượng tiểu câu được cải thiên sớm sau 4 tuần điều trị và mức tăng này vấn tiếp tục sau 12 tuân điêuu trị. Phác đô grazoprevir/elbasvir, sofosbuvir/daclatasvir, sofosbuvir/ ledipasvir vẫn giữ được mức tăng số lượng tiểu câu sau khi đat SVR. Kết liuân: Các phác đồ DAA có hiẹu quả cải thiện số lượng tiểu câuu ở bệnh nhân viêm gan virus $\mathrm{C}$ man.

Từ khóa: DAA, viêm gan C mạn, số lượng tiểu câu

\section{SUMMARY}

EFFICACY OF DIRECT-ACTING ANTIVIRUS AGENTS FOR THE PLATELET COUNT IMPROVEMENT IN CHRONIC HEPATITIS C VIRUS PATIENTS

Objective: To investigate the efficacy of directacting antiviral drugs (DAAs) for the platelet count improvement in chronic hepatitis $\mathrm{C}$ patients. Methods: A retrospective cross-sectional study was conducted on 109 medical records of outpatients with chronic hepatitis $C$ virus, treated at the Liver Clinic, University Medical Center HCMC from 01/2016 to $6 / 2020$. Patients were indicated DAAs (without IFN or ribavirin) and platelet counts were tested before, during and 12 weeks after the end of treatment. Results: The mean age of patients was $58.3 \pm 12.6$, with a higher rate of women than men and patients without cirrhosis account for high rate. The platelet counts increased as early as 4 weeks after treatment and this increasement persisted at 12 weeks after

*Đai hoc Y Dước Thành phố Hồ Chí Minh

Chịu trách nhiệm chính: Võ Duy Thông

Email: duythong@ump.edu.vn

Ngày nhận bài: 4.01.2021

Ngày phản biên khoa hoc: 26.2.2021

Ngày duyệt bài: 5.3 .2021
Võ Duy Thông*, Bùi Thị Thu Vân*

treatment Grazoprevir/elbasvir, sofosbuvir/daclatasvir, and sofosbuvir/ledipasvir kept the platelet counts increasing after SVR attainment. Conclusion: DAAs are effective for the the platelet count improvement in chronic hepatitis $C$ patients.

Key words: DAA, chronic hepatitis C virus, platelet count

\section{I. ĐĂT VẤN ĐỀ}

Bệnh viêm gan virus $C$ mạn là bệnh truyên nhiễm do virus viêm gan $C$ (Hepatitis C Virus HCV) gây ra. HCV có thể gây viêm gan cấp, viêm gan mạn, tiến triển thành xơ gan, ung thư tế bào gan [1]. Ngoài những biến chứng nguy hiểm tại gan, còn có những biến chứng khác ngoài gan như viêm khớp, viêm giác mạc, bệnh về da mạn tính, viêm câuu thận, thiếu máu tan máu tự miễn [2]. Nhiếm HCV là một trong những nguyên nhân gây ra giảm tiểu câu. Giảm tiểu câu ở bệnh nhân mắc bệnh gan mạn tính tương đối phổ biến, đặc biệt là ở bệnh nhân bị nhiễm HCV mạn. Tỷ lệ mắc khoảng $6 \%$ ở bệnh nhân bệnh gan mạn tính, 24\% ở bệnh nhẩn nhiễm HCV mạn và lên đến $78 \%$ ở bệnh nhân xơ gan [3]. Bệnh nhân nhiễm HCV mạn tiến triển thành xơ gan làm suy giảm sản xuất thrombopoietin, một cytokine tạo huyết khối, tham gia vào quá trình trưởng thành của megakaryocyte và sản xuất tiểu cầu. Việc đạt được đáp ứng virus bền vững (SVR) sau khi điều trị bằng thuốc kháng virus trực tiếp (DAA) giúp cải thiện tình trạng xơ hóa gan và một số biểu hiện ngoài gan, điều này có thể giúp cải thiện số lượng tiểu cầu. Tác dụng cửa DAA đối với việc cải thiện số lượng tiểu câu vẫn chưa được biết rõ. Do đó, chúng tôi thực hiên nghiên cứu này nhằm khảo sát hiệu quả cải thiện số lượng tiểu câu trong và sau khi điều trị bằng DAA ở bệnh nhân viêm gan virus $C$ mạn.

II. ĐỐI TƯỢNG VÀ PHƯƠNG PHÁP NGHIÊN CƯUU

Thiết kế nghiên cứu: Mô tả cắt ngang hôi cứu trên hồ sơ bệnh án của bệnh nhân viêm gan virus C mạn.

Đối tượng nghiên cứu

Tiêu chuân chọn bệnh nhân nghiên cứu: Hồ sơ bệnh án bệnh nhân bị viêm gan virus $C$ 
man, >18 tuổi trở lên, được chỉ định điều tri bẳng các phác đồ DAA (không có IFN và ribavirin), có xét nghiệm số lượng tiểu cầu trước, trong và sau khi kết thúc điêu trị 12 tuần tại Phòng khám viêm gan, Khoa khám bênh, Bênh viện Đại học Y Dược TP. Hồ Chí Minh, thời gian từ tháng 01/2016 đến 06/2020.

Tiêu chuấn loại trừ: Phụ nữ có thai, bệnh nhân không sử dụng phác đồ DAA đủ thời gian quy định, bệnh nhân không được xét nghiệm số lượng tiểu cầu đầy đủ.

Cõ̃ mẫu: Lấy mẫu thuận tiện. Tất cả bệnh nhân thoả tiêu chuẩn chọn mẫu và không có tiêu chuẩn loại trừ.

Các bước tiến hành và phân tích số liệu. Số liệu nghiên cứu được thu thập tại phòng khám Viêm gan - bệnh viện Đại học Y Dược TP. Hồ Chí Minh. Các thông tin được thu thập bao gồm: Thông tin hành chính, bệnh sử, tiền căn và khám lâm sàng từng bệnh nhân. Ghi nhận kết quả lâm sàng và cận lâm sàng trước khi điều trị (T0), sau khi sử dụng phác đồ DAA được 4 tuần (T4), 12 tuần (T12) và sau khi kết thúc điêu trị 12 tuần (T24).

Kiểm soát sai lênh thông tin: Đinh nghĩa rõ và cụ thể các biến số trong nghiên cứu. Nghiên cứu viên hiểu rõ bản chất dữ liệu và nắm vững phương pháp thu nhập dữ liệu. Đối với mỗi loại thông số, chỉ sử dụng thống nhất 1 thiết bi cân đo. Nhập số liệu, phân tích và xử lý thống kê bằng phần mềm Minitab 18.

Vấn đề y đức: Nghiên cứu tiến hành đảm bảo tuân thủ các nguyên tắc đạo đức trong nghiên cứu $Y$ học và được Hội đồng đạo đức trong nghiên cứu Y sinh học của Đại học Y Dược TP. Hồ Chí Minh thông qua.

\section{KẾT QUẢ NGHIÊN CỨU}

Từ tháng 01/2016 đến tháng 06/2020 chúng tôi thu nhận được 109 bệnh nhân viêm gan virus $C$ mạn được chỉ định dùng các thuốc DAA và được đưa vào nghiên cứu.

Đặc điểm chung của dân số nghiên cứu

Đặc điểm dịch tể học và cận lâm sàng được thể hiện trong Bảng 1 . Tuổi trong dân số nghiển cứu của chúng tôi là $58,3 \pm 12,6$. Trong 109 bệnh nhân, có $39(35,8 \%)$ là nam và nữ có tỷ lệ cao hơn nhiêu với $70(64,2 \%)$ bệnh nhân. Ba bệnh đồng mắc thường gặp là gan nhiễm mõ, viêm gan virus $B$ mạn và viêm gan do rượu $(11,0 \% ; 5,5 \%$ và $1,8 \%)$. Kiểu gen $\mathrm{HCV}$ gặp trong nghiên cứu nhiêu nhất là týp $6(47,7 \%)$, tiếp đến là týp $1(35,8 \%)$, týp 2 và không xác định kiểu gen chiếm tỳ lệ thấp $(10,1 \%$ và $6,4 \%)$.
Trong các mức độ xơ hoá gan, phần lớn của nhóm nghiên cứu là không xơ hoá (F0 - F1) có tỷ lệ $74,3 \%$. Phác đồ Sofosbuvir/Ledipasvir được sử dụng nhiều nhất (52,3\%). Đáp ứng virus nhanh (RVR) đạt được ở 85,3\% bệnh nhân, tuy nhiên tất cả bệnh nhân đều đạt được đáp ứng virus bền vững $(100 \%)$.

Bảng 1. Đặc điểm của mẫu nghiên cứu

\begin{tabular}{|c|c|}
\hline Giá trị & Tống ( $\mathrm{n}=109)$ \\
\hline Tuối (năm) (TB \pm ĐLC*) & $58,3 \pm 12,6$ \\
\hline Giới tính [n (\%)] & \\
\hline $\mathrm{Nam}$ & $39(35,8 \%)$ \\
\hline Nữ & $70(64,2 \%)$ \\
\hline Bệnh đồng mắc [n (\%)] & \\
\hline Gan nhiễm mõ & $12(11,0 \%)$ \\
\hline Viêm gan virus $B$ mạn & $6(5,5 \%)$ \\
\hline Viêm gan do rượu & $2(1,8 \%)$ \\
\hline Kiểu gen [n (\%)] & \\
\hline Týp 1 & $39(35,8 \%)$ \\
\hline Týp 2 & $11(10,1 \%)$ \\
\hline Týp 6 & $52(47,7 \%)$ \\
\hline Không xác định & $7(6,4 \%)$ \\
\hline Mức độ xơ gan [n (\%)] & \\
\hline Không xơ gan & $81(74,3 \%)$ \\
\hline Xơ hóa & $2(1,8 \%)$ \\
\hline Xơ gan còn bù & $21(19,3 \%)$ \\
\hline Xơ gan mất bù & $5(4,6 \%)$ \\
\hline $\begin{array}{c}\text { HCV RNA }\left(\log _{10} \mathrm{IU} / \mathrm{ml}\right) \\
\text { (Trung vị - KTPV) }\end{array}$ & $\begin{array}{c}5,95(4,97- \\
6,79)\end{array}$ \\
\hline ALT (U/L) (Trung vị - KTPV**) & $45(26,5-67)$ \\
\hline AST (U/L) (Trung vị - KTPV) & $45,3(30,5-70)$ \\
\hline GGT (U/L) (Trung vị - KTPV) & $51(28-96,5)$ \\
\hline Phác đồ điều trị [n (\%)] & \\
\hline Sofosbuvir/Ledipasvir & $57(52,3 \%)$ \\
\hline Sofosbuvir/Velpatasvir & $32(29,4 \%)$ \\
\hline Sofosbuvir/Daclatasvir & $18(16,5 \%)$ \\
\hline Elbasvir/Grazoprevir & $2(1,8 \%)$ \\
\hline Hiệu quả điều trị [n (\%)] & \\
\hline Đáp ứng virus nhanh (RVR) & $93(85,3 \%)$ \\
\hline Đáp ứng virus bền vững (SVR) & $109(100 \%)$ \\
\hline
\end{tabular}

*TB \pm ĐLC: Trung bình \pm Độ lệch chuẩn; ${ }^{* *} \mathrm{KTPV}$ : Khoảng tứ phân vị

Hiệu quả cải thiện số lượng tiểu câu của thuốc kháng virus trực tiếp ở bệnh nhân viêm gan virus $\mathbf{C}$ mạn

Số lượng tiểu câu trước khi điêu trị (T0): số lượng tiểu cầu (Trung vị - KTPV) được xét nghiệm trước khi bắt đầu điều trị theo từng phác đồ DAA: sofosbuvir/ledipasvir 202 (158,5 $258,5)$; sofosbuvir/velpatasvir 193,5 (135,8$230,5)$; sofosbuvir/daclatasvir $188(145-246,5)$; grazoprevir/elbasvir 102 (89 - 115).

Số lượng tiểu câu sau khi dùng thuốc 4 
tuân (T4): số lượng tiểu cầu (Trung vị - KTPV) được xét nghiệm sau khi dùng thuốc 4 tuần theo từng phác đồ DAA: sofosbuvir/ledipasvir 216 (167 - 273,5); sofosbuvir/velpatasvir 197 (144,5230,8); sofosbuvir/daclatasvir 199 (158 - 261); grazoprevir/elbasvir 123,5 (113 - 134).

Số lượng tiểu câu khi kết thúc điều trị (T12): số lượng tiểu câu (Trung vị - KTPV) được xét nghiệm khi kết thúc điều trị theo từng phác đồ DAA: sofosbuvir/ledipasvir $212(169-266)$; sofosbuvir/velpatasvir $203 \quad(141,8-252,8)$; sofosbuvir/daclatasvir $\quad 207,5 \quad(150-274,3)$; grazoprevir/elbasvir 115,5 (87 - 144).

Số lượng tiểu câu sau khi kết thúc điêu trị 12 tuần (T24): số lượng tiểu cầu (Trung vị KTPV) được xét nghiệm khi kết thúc điều trị theo từng phác đồ DAA: sofosbuvir/ledipasvir 214 $(161,5$ - 260); sofosbuvir/velpatasvir 185,5 $(149,5$ - 240,3); sofosbuvir/daclatasvir 221 (144 - 305,3); grazoprevir/elbasvir 117 (108 - 126).

So sánh về số lượng tiểu cầu trước, trong và sau khi điều trị của các phác đồ DAA được thể hiện trong Biểu đồ 1.

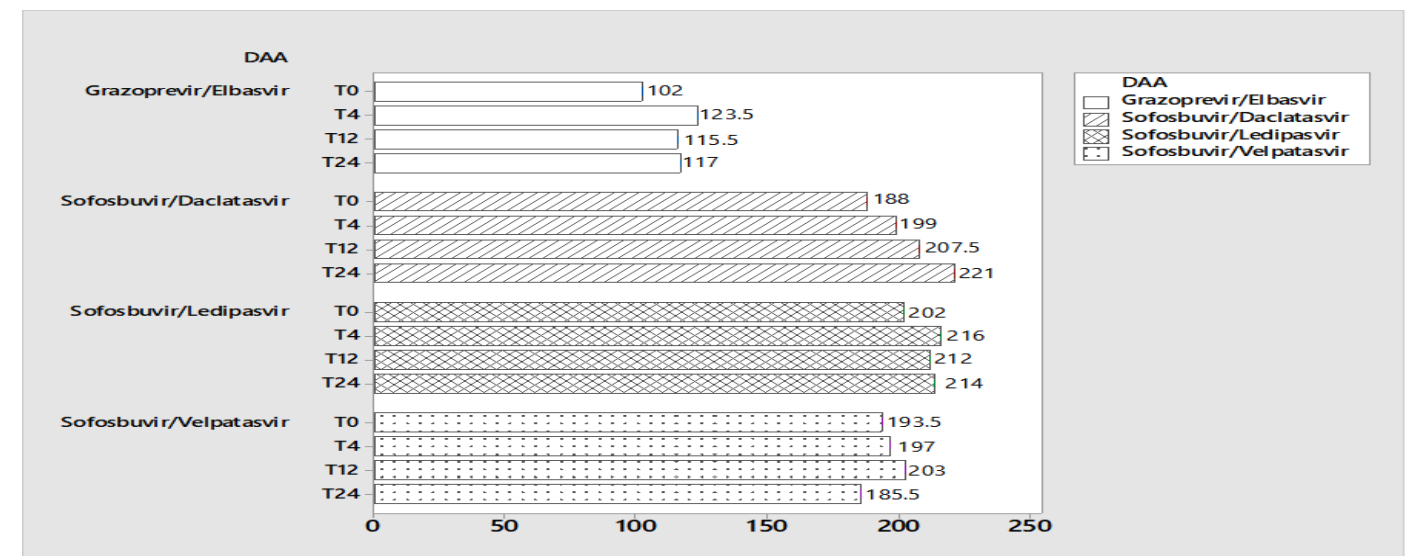

Biểu đồ 1. Số lượng tiểu cầu trước, trong và sau khi điều trị của các phác đồ

\section{BÀN LUÂ̂N}

Có khoảng $64 \%$ đến $76 \%$ bệnh nhân xơ hóa và xơ gan liên quan đến nhiễm HCV mạn có biểu hiện giảm tiểu cầu. Giảm tiểu cầu có liên quan chặt chẽ với mức độ xơ hóa gan do mức thrombopoietin thấp. Giảm tiểu cầu cũng có liên quan đến nguy cơ mắc bệnh và tử vong do xơ gan cao hơn. Do đó, điều trị sớm nhiểm HCV trước khi xuất hiện giảm tiểu cầu là cần thiết [4]. Tỷ lệ giảm tiểu cầu ở bệnh nhân viêm gan virus C mạn dao động từ $0,16 \%$ đến $45,4 \%$, hầu hết các nghiên cứu báo cáo tỷ lệ này > 20\% [5]. Một số nghiên cứu cho thấy số lượng tiểu cầu đã tăng lên đáng kể ở bệnh nhân viêm gan virus $C$ mạn sau khi điều trị DAA thành công. Sự cải thiện đáng kể về tiểu cầu được xác định khi số lượng tiểu câuu tăng hơn $10 \%$ so với số lượng ban đâu. Trong nghiên cứu của chúng tôi đã thu nhận được 109 hồ sơ bệnh án bệnh nhân viêm gan virus $C$ mạn, được chỉ định dùng 1 trong 4 phác đồ DAA và có đầy đủ giá trị cận lâm sàng cân thiết.

Đa số bệnh nhân là nữ giới (64,2\%), độ tuổi trung bình trong mẫu nghiên cứu là $58,3 \pm 12,6$. Kết quả này tương đồng với nghiên cứu của Lý Thị Kim Dung (2016) trên 282 bệnh án của bệnh nhân viêm gan virus $C$ mạn [6]. Tỷ lệ bệnh nhân bị xơ gan trước khi điều trị là $23,9 \%$, trong đó xơ gan mất bù chiếm $4,6 \%$.

Phác đồ grazoprevir/elbasvir làm tăng số lượng tiểu cầu sau 4 tuần điều trị $21,5 \mathrm{G} / \mathrm{L}$ $(17,4 \%), 12$ tuần $13,5 \mathrm{G} / \mathrm{L}(11,7 \%)$, 24 tuần 15 G/L (12,8\%). Điều trị DAA làm tăng đáng kể số lượng tiểu cầu sớm nhất là 4 tuần sau khi điều trị, mức tăng này vẫn tiếp tục duy trì sau khi kết thúc điều trị 12 tuần, nghiên cứu của chúng tôi tương đồng với nghiên cứu của Chen Y. C. và cộng sự (2020) (> 10\% so với ban đâu) [5].

Phác đồ sofosbuvir/daclatasvir làm tăng số lượng tiểu cầu sau 4 tuân điêuu trị $11 \mathrm{G} / \mathrm{L}(5,5 \%)$, 12 tuần 19,5 G/L (9,4\%), 24 tuần $33 \mathrm{G} / \mathrm{L}(14,9 \%)$.

Phác đồ sofosbuvir/ledipasvir làm tăng số lượng tiểu cầu sau 4 tuần điều trị $14 \mathrm{G} / \mathrm{L}(6,5 \%)$, 12 tuần $10 \mathrm{G} / \mathrm{L}(4,7 \%)$, 24 tuần $12 \mathrm{G} / \mathrm{L}(5,6 \%)$, nghiên cứu của chúng tôi tuy có tỷ lệ tăng số lượng tiểu cầu thấp hơn báo cáo của Alcazer $V$. và cộng sự (2018), nhưng Alcazer V. chỉ báo cáo trên 1 bệnh nhân nhiễm HCV bị giảm tiểu cầu nghiêm trọng [7].

Phác đồ sofosbuvir/velpatasvir làm tăng số lượng tiểu cầu sau 4 tuần điều trị $3,5 \mathrm{G} / \mathrm{L}$ $(1,8 \%), 12$ tuần $9,5 \mathrm{G} / \mathrm{L}(4,7 \%)$, tuy nhiên sau 
24 tuần số lượng tiểu cầu giảm $8 \mathrm{G} / \mathrm{L}(4,3 \%)$, trong nghiên cứu của Gayam V. và cộng sự số lượng tiểu cầu giảm $8 \%$.

Sự cải thiện số lượng tiểu cầu sau khi điều trị DAA còn phụ thuộc vào nhiều yếu tố khác nhau như mức thrombopoietin ban đâu theo nghiên cứu của Chen Y. C.[3]; gan nhiếm mõ trung bình hoắc nặng có liên quan đáng kể đến việc cải thiển số lương tiểu câuu theo nghiên cứu của Chen Y. C. [5]; sự thay đổi số lượng tiểu cầu sau khi đạt SVR có liên quan đến sự thay đổi thể tích gan trong nghiên cứu của Seko Y. [8].

\section{KẾT LUẬN}

Kết quả nghiên cứu cho thây, số lượng tiểu cầu tổng thể đã tăng lên đáng kể ở bệnh nhân nhiễm HCV được điều trị bằng DAA. Cả 4 phác đồ DAA đều giúp số lượng tiểu câu được cải thiện sớm sau 4 tuần điều trị và mức tăng này vẫn tiếp tục sau 12 tuần điêu trị. Phác đồ grazoprevir/elbasvir, sofosbuvir/daclatasvir, sofosbuvir/ledipasvir vẫn giữ được mức tăng số lượng tiểu cầu sau khi đạt SVR. Phác đồ sofosbuvir/velpatasvir có số lượng tiểu cầu giảm sau khi đạt SVR, nguyên nhân giảm cần được nghiên cứu thêm.

\section{TÀI LIẸU THAM KHẢO}

1. Bộ Y Tế, Hướng dẫn chẩn đoán và điều tri viêm gan virus $C$ (Ban hành kèm theo Quyết định số 5012/QĐ-BYT ngày 20/09/2016 của Bộ trưởng Bộ Y tế). 2016

2. Hoofnagle J. H. (1997). Hepatitis C: the clinical spectrum of disease. Hepatology (Baltimore, Md. ), 26(3 Suppl 1), pp. 15S-20S.

3. Chen Y. C., Ko P. H., Lee C. C., Tsena C. W., \& Tsena K. C. (2021). Baseline thrombopoietin level is associated with platelet count improvement in thrombocvtopenic chronic hepatitis $\mathrm{C}$ patients after successful direct-acting antiviral agent therapy. BMC qastroenteroloqv, 21(1), 30.

4. Gavam V., Mandal A. K., Khalid M., Mukhtar O. Gill A., Garlapati P., Khalid M., \& Mansour M. (2018). Sofosbuvir Based Reqimens in the Treatment of Chronic Hepatitis C with Compensated Liver Cirrhosis in Communitv Care Setting. International iournal of hepatoloav, 2018, 4136253.

5. Chen Y. C., Tsenq C. W., \& Tseng K. C. (2020). Rapid platelet count improvement in chronic hepatitis C patients with thrombocvtopenia receivina direct-actina antiviral agents. Medicine, 99(19), e20156.

6. Lý Thị Kim Dung. Khảo sát tình hình sử dụng và hiệu quả điều trị viêm gan siêu vi $C$ mạn của thuốc kháng virus trực tiếp tai bênh viên Đai hoc $\mathrm{Y}$ Dược TP. HCM. Luận văn thạc sĩ dược học, Trường Đại Hoc Y Dước TंP. HCM. 2017.

7. Alcazer V., Miailhes P., Ramière C., Charre C. \& Cotte L. (2018). Earlv sofosbuvir-ledipasvir treatment for acute HCV infection induced severe immune thrombocytopenia - a case report. BMC infectious diseases, 18(1), 682.

8. Seko Y., Moriquchi M., Takahashi A., Okishio S., Kataoka S., Okuda K., Mizuno N., Takemura M., Taketani H., Umemura A., Nishikawa T., Yamaquchi K., \& Itoh Y. (2020). The Association between the Platelet Count and Liver Volume in Compensated Cirrhosis Patients after the Eradication of Hepatitis $C$ virus by Direct-actina Antivirals. Internal medicine (Tokyo, Japan), 59(15), 1811-1817.

\section{THIẾT LÂPP MẪU MÁU GIẢ ĐİNH CHỨA VI KHUẨN STAPHYLOCOCCUS AUREUS DÜNG TRONG NGOÅI KIỂM}

\section{TÓM TẮT}

Mục tiêu: Thiết lập mẫu máu giả định chứa $\mathrm{S}$. aureus sử dụng cho chương trình ngoại kiểm chất lượng vi sinh đạt độ đồng nhất và ổn định theo ISO 17043:2011. Phướng pháp: Nghiên cứu thực nghiệm. Đánh giá tốc độ tăng trưởng của và S. aureus trong môi trường máu giả định có và không có acid boric và natriformat. Xác định nồng độ acid boric và

*Đại hoc Y Dược Tp. Hồ Chí Minh

**iêenh viện Truyến máu Huyết họ Tp. Hồ Chí Minh

Chịu trách nhiệm chính: Hà Mạnh Tuấn

Email: hamanhtuan@ump.edu.vn

Ngày nhận bài: 5.01.2021

Ngày phản biện khoa học: 24.2.2021

Ngày duyệt bài: 5.3 .2021

\section{Hà Mạnh Tuấn*, Nguyễn Thị Thu Diểm**}

natriformat phù hợp. Thử nghiêm sản xuất bô mẫu máu giả định chứa cơ chất nutrient broth, máu cừu, acid boric và natrifomat theo nồng độ đã xác định. Sứ dụng phép kiểm T-Student và Onewaỹ ANOVẢ đánh giá tính đồng nhất, tính ổn định bộ mẫu máu giả định đã sản xuất. Kết quả: Sử dụng acid boric và natrifomat duy trì nồng độ $\mathrm{S}$. aureus trong mẫu (máu cứu, nutrient broth) hiệu quả hơn so với không sử dung. Nông đô acid boric $8 \%$ và natriformat $4 \%$ là phù hợp với sản xuất mẫu máu giả định vi khuẩn đích là S.aureus. Bô mẫu sản xuất chứa vi khuẩn đích $\mathrm{S}$.

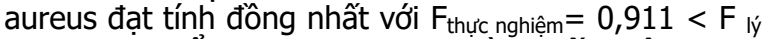
thuyết $=3,02$, ổn định trong 17 ngày. Kết luân: Qua nghiên cứu, sử dụng acid boric- natrifomat làm chất bảo quản trong môi trường máu giả định là phù hợp. Thiết lập thành công bộ mẫu máu giả định $\mathrm{S}$. aureus sử dụng cho chương trình ngoại kiểm vi sinh theo tiêu 